\title{
ANALYSIS OF SECOND-ORDER EFFECTS EVALUATION OF STEEL FRAMES BEHAVIOUR
}

\author{
Raminta VENSLAVAVIČIŪTEE ${ }^{*}$, Kęstutis URBONAS, Vaidotas ŠAPALAS \\ Department of Steel and Composite Structures, Vilnius Gediminas Technical University, Vilnius, Lithuania
}

Received 13 May 2020; accepted 15 July 2020

\begin{abstract}
The evaluation of second-order effects of steel framed structures can provide different analysis results than using linear analysis methods. In various structural engineering literature were distinguished different methods of analysis: taking or without taking into account second-order effects. It depends on the sensitivity to the horizontal actions. The slenderer the structure, the more sensitive it is to horizontal actions. Using nonlinear methods, the sensitivity of steel frame to second-order impact is considered. This paper shows the importance of evaluations of the second-order effects in behaviour of steel frame structures. Performed investigations reveal the influence of the rotational stiffness of the joints to the behaviour of whole framed structure. Calculation results show that decreased flexibility of the semi-rigid joints increase sensitivity of the framed structure to the second-order effects and vice versa. The identified interdependence between the sensitivity to the second-order effects and the flexibility of the semi-rigid joints highlights the importance of evaluation of such dependencies.
\end{abstract}

Keywords: numerical modelling, steel framed structures, structural analysis, second-order analysis, Eurocode 3, semi-rigid joints, sensitivity to the second-order effects.

\section{Introduction}

Modern construction industry focuses on the rational design of sustainable building. The challenges of recent sustainable development require a reliable solution (Zavadskas et al., 2013), which, in many cases, is characterized by accurate structural analysis and advanced design solutions (Turskis et al., 2019). Steel structures, compared with the other, are slender (Giżejowski et al., 2017), and chosen analysis and numerical modelling methods could have huge impact to the design result of the framed structure (Kala, 2016) and selection of steel elements (Morkhade \& Gupta, 2015). Slenderness of steel structures are the determining factor for design sensitivity for second-order impacts (Yoo \& Lee, 2011). The second-order effects analysis differs from the first-order by the fact that the deformed shape of the structure is evaluated. Deformed shape of the structure (second-order factors) must be taken into account if they significantly change the value of internal forces or substantially change the behaviour of the structure (Dell'Aglio et al., 2019; Park \& Yeo, 2017). Additional aim of this paper is to show the close relationship between behaviour of semi-rigid joints and the need to use the second-order analysis.
Literature analysis shows, that there are a lot of options for the designer himself to decide how to evaluate the effects of the structural nonlinearities (Silva et al., 2013; Walport et al., 2019). The calculations of steel frame structures do not specify the analysis methods that properly evaluate the sensitivity of the frame to the second-order effects by introducing semi-rigid joints. In reality we can not ignore flexibility of the joints, as well as the second-order effects in steel frame structures (Chiorean, 2017). These factors as individually acting have been extensively analysed long ago, but the combined effect of the two and specifically the influence of semi-rigid joints on second-order effects is not widely analysed in the literature. According to this and the lack of experience in the usage of techniques that causes the misinterpretation of the results (Truong et al., 2017; Bhatti, 2017; Kim \& Troung, 2020).

\section{Methods of analysis of steel frames}

Cross-beam deforms horizontally, but joint of the left corner of the frame does not have a horizontal displacement until reaching the critical load - it provides the classi-

${ }^{*}$ Corresponding author. E-mail: raminta.venslavaviciute@vgtu.lt 
cal theory of Euler. However, depending on the column slenderness, the residual stresses and initial imperfections have a significant effect on the load bearing capacity of the column (Desai, 2018). These factors determine that the structure gradually horizontally deformed before reaching the critical load. This deformation affects the appearance of secondary second-order moments, which further reduces the structural bearing capacity. In the literature, the second-order global (frame) and local (element) effects are often divided into (frame) P- $\Delta$ and P- $\delta$ (element) (see Figure 1). P- $\delta$ effects occur along the element, and at the ends of the elements P- $\Delta$ (Ziemian, 2010).

The main purpose of the article is to show the sensitivity of the frame structures for the second-order impacts and the meaning of this $\alpha_{c r}$ coefficient as compared to the full second-order analysis; to study the influence of semirigid joints when second-order effects are evaluated. In order to achieve the results, it is used the elastic second-order analysis which is permitted in all cases. Therefore, the code provides three main methods for assessing the effects of the second-order and the deformations according to the type of frame and the chosen type of overall analysis (see European Comitee for Standardization [CEN], 2005a):

1) In basic, simple cases - checking the stability of individual elements. Here the buckling length is taken under the common form of buckling;

2) By partially applying an overall analysis, and partly by checking the stability of the individual elements;

3) A detailed second-order analysis is applied.

This paper presents the analysis of steel frame structures with different stiffness of joints is considered. Because joints tend to deform due to bending moments of the operation are generally critical and has the largest influence on the results obtained in the analysis of structures (Yoo \& Lee, 2011). Frame structure is considered without bracing members, although they are often an integral part of frame structures that have a significant effect on their behaviour (Králik, 2013), but this work does not take into account their influence. Steel frames are only analysed in a plane of the frame. The analysis of the frame is only in-elastic second-order analysis (analysing only geometric nonlinearities) is considered (The Steel Construction Institute, 2009).

\section{Sensitivity of the steel frame to second-order effects}

Sensitivity to second-order effects (CEN, 2005a; Silva et al., 2013) is determined using the elastic critical load $F_{c r}$ and active force $F_{E d}$ ratio, expressed through the coefficient $\alpha_{c r}$. This coefficient is calculated by using Equation (1), the results obtained from the stability analysis, taking into account the original design geometry and common initial inclination:

$$
\alpha_{c r}=\frac{F_{c r}}{F_{E d}},
$$

where: $\alpha_{c r}$ - the factor by which the design loading would have to be increased to cause elastic instability in a global mode; $F_{c r}$ - the elastic critical load; $F_{E d}$ - active force.

The beams and columns plane type frames may be considered as restrained from horizontal displacements, so the analysis of the first-order $\alpha_{c r}$ counted in each floor.

a) sway permitted
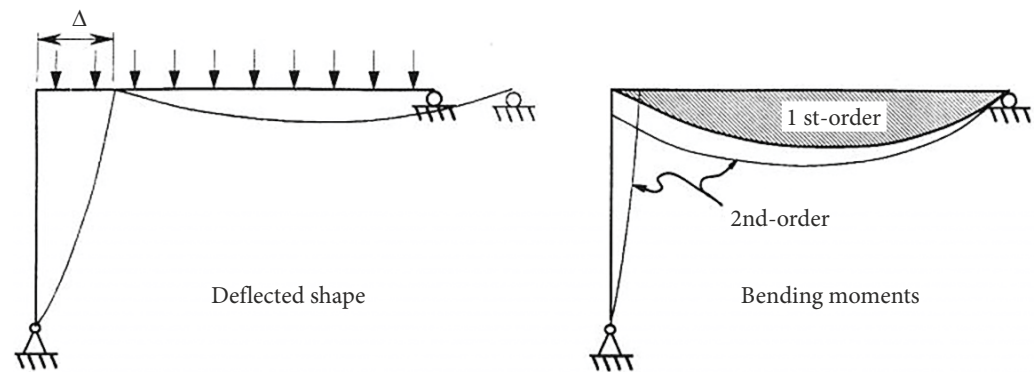

b) sway restrained
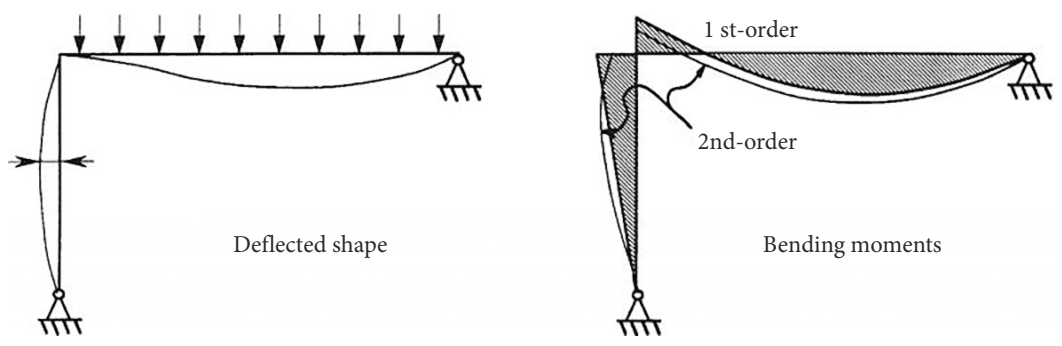

Figure 1. Second-order effects P- $\Delta$ and P- $\delta$ (source: Ziemian, 2010) 
Using analytical Equation (2), frames with rigid joints sensitivity of the second-order effects:

$$
\alpha_{c r}=\frac{H_{E d}}{V_{E d}} \cdot \frac{h}{\delta_{H, E d}},
$$

where: $H_{E d}$ - the total design horizontal load transferred by the storey (storey shear); $V_{E d}$ - the total design vertical load on the frame transferred by the storey (storey thrust); $\delta_{H, E d}$ - the horizontal displacement at the top of the storey; $h$ - the storey height.

For multi-storey frames second-order effects may be approximately calculated by increasing the horizontal loads $H_{E d}$ (e.g. wind) and equivalent loads $V_{E d} \phi$ due to imperfections according to the first order theory by the factor:

$$
\frac{1}{1-\frac{1}{\alpha_{c r}}}
$$

On condition that $\alpha_{c r} \geq 3.0$, where $\alpha_{c r}$ is been calculated according Equation (2).

EN 1993-1-1 (CEN, 2005a) allows simplification of second-order effects evaluation when $\alpha_{c r}$ value is between 3 and 10. This allows much shorten the course of the calculations and make them faster than the full second-order analysis, and the results are close enough.

Before starting to analyse the structures of steel frames, there are restrictions that apply throughout the analysis. According to this analysing the selected frame in the second limit state conditions have been previewed, but it was not the primary criterion for assessing the behaviour of the steel frame. The cross sections of the frame were selected based on the load bearing capacity of the element when designing the model for overall analysis, however the requirements of the serviceability limit state have not been applied.

\section{Calculations of the frame with ideally rigid joints}

As mentioned before, one of the aims of this paper is to show the close relationship between behaviour of semirigid joints and the need to use the second-order analysis. First of all, to obtain the results of this relationship, the calculations were started using rigid joints in the struc- ture. After the results were obtained, the semi-rigid joints were introduced to the structure.

Calculations were performed with one-storey, twoand three-storey frame structures. The paper presents the results of a two-storey frame structure because they adequately reflect the pattern of behaviour of frame structures. The behaviour of one-storey frame is reflected by the behaviour of the upper floor. And the behaviour of a three-storey frame is similar to the behaviour of a twostorey frame structure. The only difference is that the sensitivity of the first floor of a three-storey frame to horizontal effects is even higher than that of a two-storey frame.

Numerical calculations are performed with a multi support two-story steel frame which is covered by three different loading schemes. Joints of the frame accepted as rigid ones. The frame is loaded by permanent, imposed and variable loads, including the fictitious horizontal loads that model the imperfections of the frame. It involves operating load combinations for computational models are obtained: in a first case of a first combination predominant load is the usage or snow load, and in the second case predominant load is wind load. And changing the distribution of the imposed load on the floor precisely generates 3 computational load combinations. The general scheme of the frame with the layout of the elements is shown in Figure 2.

Steel frame is calculated using a loading scheme where the imposed load on the intermediate floor is distributed in three different ways in order to know which version of the load distribution is the most dangerous and the most affective for second-order effects. In the first case, the imposed load is evenly distributed on the intermediate floor. In the second case, the load is distributed in chess order and finally, in the last case, the load is distributed only in the middle span of the frame. Initial calculations using these loading methods were found to be the most sensitive loading option when the imposed load is evenly distributed across the floor on the intermediate floor (see Figure 3). In the initial calculations, it was also observed that either the prevailing snow or the wind do not, in real conditions, significantly affect the occurrence of second-order effects in the plane of the metal frame. Therefore, the secondorder effects are most influenced by the interacting load on the intermediate floor and it should be emphasized that the second storey of the frame at the level of the intermediate floor is more sensitive to second-order effects.

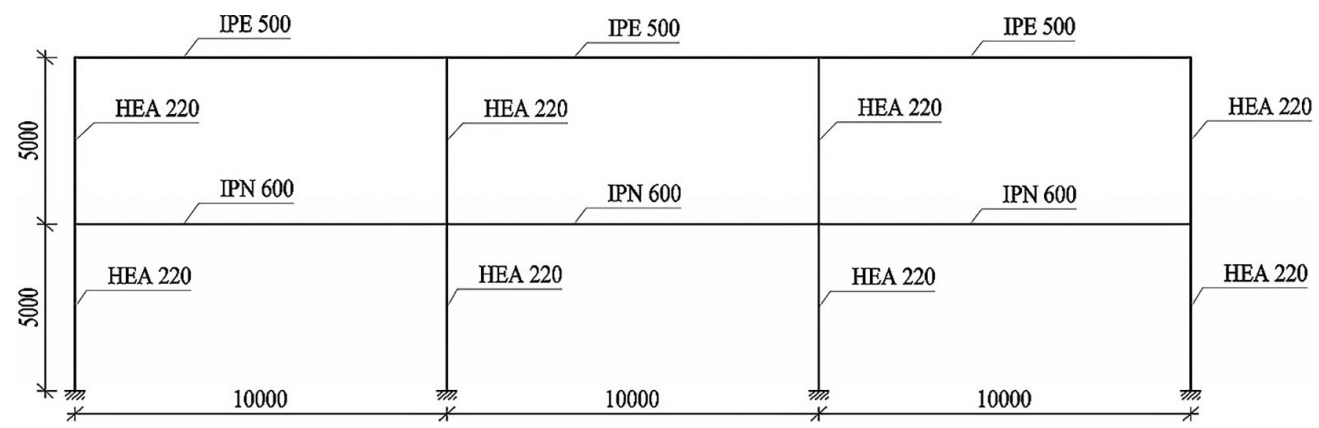

Figure 2. The general scheme of the frame 


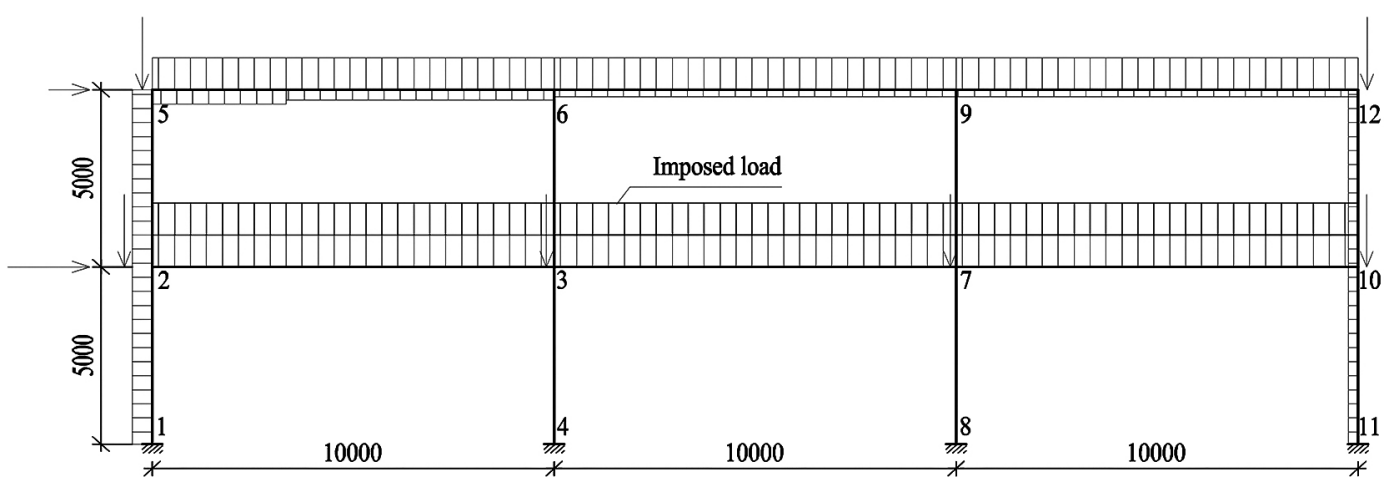

Figure 3. Loading scheme where the imposed load evenly distributed over the entire first floor

To determine the sensitivity to second order effects $\alpha_{c r}$ criterion was used.

The actual load situation with pre-set frame columns and beam profiles are analysed.

The calculations of the steel multi-storey frame performed using different methods of analysis, i.e. the firstorder analysis, taking into account the initial geometry of the design and adapting the general initial inclination for the rigid frame. Also, the same frame is calculated applying a semi-rigid joint. But more about these calculations see next chapter of this article. According to literature (CEN, 2005a; Silva et al., 2013) the easiest way to determine the sensitivity of the second order effects is to use the analytical $\alpha_{c r}$ values of each floor. The calculations were made using all of the mentioned loading schemes. The results are presented in Table 1. Analysis results has shown that the frame structure with the rigid joints is not sensitive to second-order effects. Therefore, second-order effects do not have a significant effect on the behavior of such a frame.

\section{Calculations of frame taking into account actual rigidity of the joints}

In this chapter, the steel frame in question is determined sensitivity second-order effects analytically calculating $\alpha_{c r}$ values of each floor. According to the results observed in the steel frame with rigid joints is the least sensitive, so further checks on the calculation $\alpha_{c r}$ validity value is performed with same frame, only semi-rigid joints instead of rigid ones were used. The values of rotational stiffness of the semi-rigid joints accepted in the calculations is the average between the boundary of the pinned and rigid joints
(CEN, 2005b). Such stiffness was achieved using column web stiffeners and bolted connections.

Additional calculations were performed reduced rotaional stiffness of previously calculated semi-rigid joints by another $10 \%$.

Results of $\alpha_{c r}$ (see Table 1) shows that flexibility of the joints has direct impact to the behaviour of the framed structure and to the sensitivity of second-order effects.

In order to reveal the impact of semi-rigid joints to the sensitivity of the steel frame in Figure 2, the calculations were made to all of the combinations of imposed load. According to the combinations and load variability, the most sensitive frame is where imposed load evenly distributed over the entire first floor. Also to determine the influence of semirigid joints, two different rigidity types were used in the calculations which showed that sensitivity is further increased by flexibility of the joints (Daniūnas \& Urbonas, 2010).

According to the results of the linear analysis, the comparative analysis of the first-order theory using the load factor and the second-order theory, is chosen to carry out frame according to the loading scheme presented in Figure 3, with semi-rigid joint (more flexible).

Since the steel frame with a semi-rigid joints sensitivity to second-order effects evaluating $\alpha_{c r}$ the minimum value is less than 10, during the elastic behaviour analysis must take into account the second-order factors, if they significantly increase the internal forces, or significant changes the behaviour of structures (see CEN, 2005a). The secondorder effects are evaluated using the first-order theory of increased horizontal loads (since the value of $\alpha_{c r}$ is not less than 3) and the second-order analysis of elastic behaviour. The results of the general frame deviations (P- $\Delta$ ) obtained in these two calculations are quite close.

Table 1. Values of $\alpha_{c r}$

\begin{tabular}{|l|c|c|c|c|}
\cline { 2 - 5 } \multicolumn{1}{c|}{} & \multicolumn{2}{c|}{ Storey Nr. 1 } & \multicolumn{3}{c|}{ Storey Nr. 2 } \\
\cline { 2 - 5 } \multicolumn{1}{c|}{} & $\begin{array}{c}\text { predominant load is the } \\
\text { usage or snow load }\end{array}$ & $\begin{array}{l}\text { predominant } \\
\text { load is wind }\end{array}$ & $\begin{array}{c}\text { predominant load is the } \\
\text { usage or snow load }\end{array}$ & $\begin{array}{l}\text { predominant } \\
\text { load is wind }\end{array}$ \\
\hline Joints are rigid & 10.8824 & 13.0556 & 97.8958 & 109.714 \\
\hline Joints are semi-rigid & 7.7746 & 8.9016 & 48.9479 & 73.1429 \\
\hline Joints are semi-rigid (rigidity reduced by 10\%) & 7.2536 & 8.5135 & 48.9279 & 65.8142 \\
\hline
\end{tabular}


During the overall analysis, the focus was on semi-rigid joints, their influence on the resulting displacements and the sensitivity of the steel frame to second-order effects. The results of displacement in the frame with semi-rigid joints in the analysis based on the theory of first-order and compared with the results obtained in the second-order theory, the difference is proportional to the stiffness of the joints (see CEN, 2005b). After the first calculation with semi-rigid joints, an increase in displacement up to $21 \%$ is obtained by applying the first-order theory using load factor enhancement.

The frame is analysed by a stepwise approach of loading according to the loading principle discussed above. Initially the frame is counted linearly using rigid joints in the system and observing the displacements of the characteristic points, which measure the second effect on each floor of the plane frame. Whereas rigid frame joints have been found to cause no second-order effects, so semi-rigid joints are introduced in the computational scheme. In this case, there is a noticeable effect of these points on second-order effects. For this reason, a linear analysis of the frame is performed using a method of increasing horizontal loads to obtain displacements of characteristic points. Such analysis is performed by proportionally reducing the stiffness of the semi-rigid joint, thus observing the relationship between the rigidity of the semi-rigid joint and the characteristic displacements of the points. The final results are given in the table below (see Table 2).

The discussed calculations, when semi-rigid joints are introduced into the calculation scheme, are repeated using full second-order analysis. The results are obtained under the same conditions and with the same stiffness of the joints as in the linear method discussed above. Full second-order analysis showed greater offset of characteristic points, indicating more accurate results and greater sensitivity of the frame to second-order effects.

Compared to second-order analysis, the difference is up to $29 \%$. But with even more joints releasing, the difference decreases to $20 \%$ in one case and up to $14 \%$ in the other (see Table 3).

The default plane frame is analysed in two ways to determine second-order effects, that is, linear analysis using horizontal load enhancement and full second-order analysis. Both analyses are performed under the same conditions, only the displacement of the characteristic points is observed.

By analysing the differences between the linear analysis using load factor enhancement and second-order analysis, it can be seen that the results are close, with the difference up to $6 \%$ (see Table 4 ).

Therefore, the closer the joint is to the supposedly hinged one, the higher the nodal displacement and sensitivity of the second-order effect, which requires more detailed analysis.

After reviewing the results, the main conclusions can be drawn after comparing these results, that the link between the semi-rigid joints and the second-order effects in Euro norm is reasonable and well reflected in the results.

Collected results of the displacements using first-order theory with the load enhancement and the second-order theory, the results are very similar and differ only by $6 \%$ (see Figure 4). Where the results of different analyses are

Table 2. Results of frame deformations calculated by methods 1 and 2

\begin{tabular}{|l|c|c|c|c|}
\cline { 2 - 5 } \multicolumn{1}{c|}{} & \multicolumn{2}{c|}{ Storey No. 1 } & \multicolumn{2}{c|}{ Storey No. 2 } \\
\cline { 2 - 5 } \multicolumn{1}{c|}{} & $\begin{array}{c}\text { predominant load is } \\
\text { the usage or snow load }\end{array}$ & $\begin{array}{c}\text { predominant } \\
\text { load is wind }\end{array}$ & $\begin{array}{c}\text { predominant load is } \\
\text { the usage or snow load }\end{array}$ & $\begin{array}{l}\text { predominant } \\
\text { load is wind }\end{array}$ \\
\hline First-order analysis (method 1) & 0.015 & 0.023 & 0.021 & 0.033 \\
\hline First-order analysis with load enhancement (method 2) & 0.017 & 0.026 & 0.024 & 0.037 \\
\hline Difference in \% between types of analysis & 13.33 & 13.04 & 14.29 & 12.12 \\
\hline
\end{tabular}

Table 3. Results of frame deformations calculated by metods 1 and 3

\begin{tabular}{|c|c|c|c|c|}
\hline & \multicolumn{2}{|c|}{ Storey No. 1} & \multicolumn{2}{|c|}{ Storey No. 2} \\
\hline & $\begin{array}{l}\text { predominant load is the } \\
\text { usage or snow load }\end{array}$ & $\begin{array}{l}\text { predominant } \\
\text { load is wind }\end{array}$ & $\begin{array}{l}\text { predominant load is the } \\
\text { usage or snow load }\end{array}$ & $\begin{array}{l}\text { predominant } \\
\text { load is wind }\end{array}$ \\
\hline First-order analysis (method 1) & 0.014 & 0.022 & 0.020 & 0.031 \\
\hline Second-order analysis (method 3) & 0.018 & 0.027 & 0.024 & 0.037 \\
\hline Difference in \% between types of analysis & 28.57 & 22.73 & 20.00 & 19.35 \\
\hline $\begin{array}{l}\text { First-order analysis (method 1) } \\
\text { (rigidity reduced by } 10 \% \text { ) }\end{array}$ & 0.015 & 0.023 & 0.021 & 0.033 \\
\hline Second-order analysis (method 3) & 0.018 & 0.027 & 0.024 & 0.037 \\
\hline Difference in \% between types of analysis & 20.00 & 17.39 & 14.29 & 12.12 \\
\hline
\end{tabular}


Table 4. Results of frame deformations calculated by methods 2 and 3

\begin{tabular}{|l|c|c|c|c|}
\cline { 2 - 5 } \multicolumn{1}{c|}{} & \multicolumn{2}{c|}{ Storey No. 1 } & \multicolumn{2}{c|}{ Storey No. 2} \\
\cline { 2 - 5 } \multicolumn{1}{c|}{} & $\begin{array}{c}\text { predominant load is } \\
\text { the usage or snow load }\end{array}$ & $\begin{array}{c}\text { predominant } \\
\text { load is wind }\end{array}$ & $\begin{array}{c}\text { predominant load is } \\
\text { the usage or snow load }\end{array}$ & $\begin{array}{c}\text { predominant } \\
\text { load is wind }\end{array}$ \\
\hline First-order analysis with load enhancement (method 2) & 0.017 & 0.026 & 0.024 & 0.037 \\
\hline Second-order analysis (method 3) & 0.018 & 0.027 & 0.024 & 0.037 \\
\hline Difference in \% between types of analysis & 5.88 & 3.85 & 0.00 & 0.00 \\
\hline
\end{tabular}

presented where the uniform imposed load distribution is the same in each case. The frame joints were equally released for each analysis. Graphically shows the maximum displacements of the characteristic frame nodes during each analysis, allowing for analytical comparison of the results obtained and to make valid conclusions.

The greatest influence on the results obtained is not the arrangement of the loads, nor the imposed load, but the joints of the frame. Therefore, the more the joint approaches the folding, the greater the displacements and the lower value of $\alpha_{c r}$ this means a growing need for more accurate calculations of performance.

As mentioned at the beginning of the chapter 3, the calculations were performed with one-storey, two- and three-storey frame structures. The behaviour of the onestorey frame is well reflected by the behaviour of the upper-floor two-storey frame. And the behaviour of a threestorey frame is similar to the behaviour of a two-storey frame structure. The only difference is that the sensitivity of the first floor of a three-storey frame to horizontal effects is even higher than that of a two-storey frame. Therefore, the higher the building, the lower the storeys of the building become more sensitive to horizontal displacements and at the same time to the second-order effects.

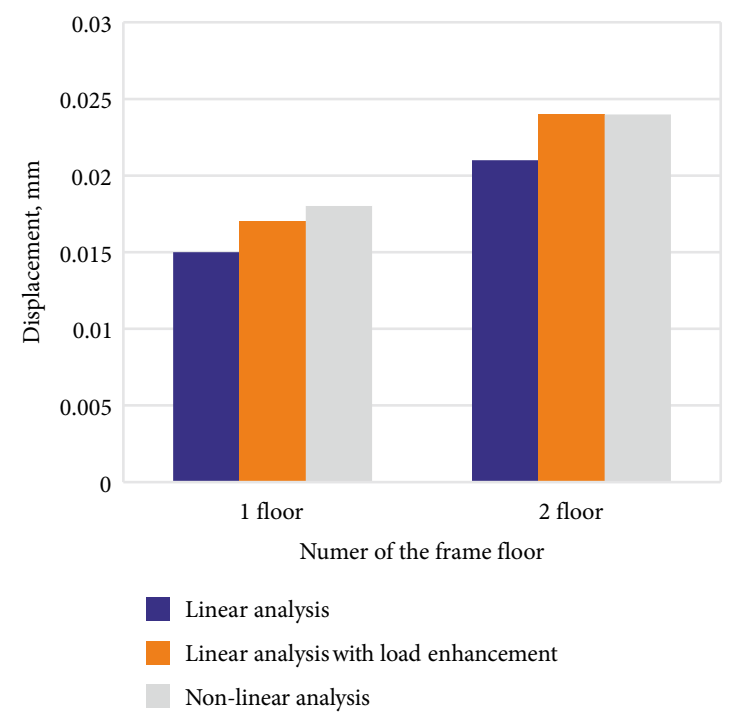

Figure 4. Comparison of different types of analysis of displacements

\section{Conclusions}

1. The analysis of the influence of joints' rotation stiffness on the behaviour of steel frame was performed. The results show that the joints are more flexible, the frame more sensitive to horizontal displacement and second-order effects, respectively.

2. The performed calculations showed that the rotational stiffness of the semi-rigid joints and its proportional decrease in the frame analysis influenced the sensitivity of the frame to the second-order effects. When the rotational stiffness of the semirigid joints of analyzed two-storey frame decreases by $20 \%$, then $\alpha_{c r}$ of the first storey level decreases by almost $7 \%$. At the same time, the sensitivity of the upper floor to the second-order effects changes insignificantly.

3. The comparison of horizontal displacements of the frame structure was obtained according to the following three methods:

- linear analysis without taking into account structural imperfections (method 1);

- global analysis partially accounts for imperfections (global structural imperfections) and second-order effects (global effects), while individual stability checks on members (clause 6.3) intrinsically account for member imperfections and local second-order effects (method 2);

- global analysis directly accounts for all imperfections and all second-order effects (method 3$)$.

The difference in results between the method 1 and methods 2 and 3 up to 14 and 20\% respectively. Such a differences are significant. Therefore, secondorder effects need to be evaluated.

While the difference in results between methods 2 and method 3 is up to $6 \%$. Thus, either of these two methods can be used. However, method 2 has shown a slightly larger displacement.

4. The Eurocode focuses on the design of steel frames using semi-rigid joints. The use of flexible semi-rigid joints increases the importance of second-order effects for the behaviour of structures. Therefore, in many cases, geometric nonlinearities need to be considered when analysing two-story and taller buildings. The results of the analysed two-storey framed structure show that. 


\section{Funding}

No funding and grant-awarding bodies.

\section{Author contributions}

Raminta Venslavavičiūtė: Software, Validation, Data Curation, Analysis Writing - Original Draft, Review \& Editing; Kęstutis Urbonas: Conceptualization, Methodology, Writing - Review \& Editing; Vaidotas Šapalas: Supervision, Software, Writing - Review \& Editing.

\section{Disclosure statement}

The authors declare that they have no known competing financial, professional, or personal interests that could have appeared to influence the work reported in this paper.

\section{References}

Bhatti, A. Q. (2017). Dynamic response characteristics of steel portal frames having semi-rigid joints under sinusoidal wave excitation. International Journal of Advanced Structural Engineering, 9, 309-313.

https://doi.org/10.1007/s40091-017-0167-8

Chiorean. C. G. (2017). Second-order flexibility-based model for nonlinear inelastic analysis of 3D semi-rigid steel frameworks. Engineering Structures, 136(1), 547-579. https://doi.org/10.1016/j.engstruct.2017.01.040

Daniūnas A., \& Urbonas, K. (2010). Influence of the semi-rigid bolted steel joints on the frame behaviour. Journal of Civil Engineering and Management, 16(2), 237-241. https://doi.org/10.3846/jcem.2010.27

Dell'Aglio, G., Montuori, R., Nastri., E., \& Piluso, V. (2019).Consideration of second-order effects on plastic design of steel moment resisting frames. Bulletin of Earthquake Engineering, 17, 3041-3070. https://doi.org/10.1007/s10518-019-00573-9

Desai, P. Int. (2018). Effect of slenderness ratio on euler critical load for elastic columns with ANSYS. Journal of Engineering Research and Application, 8(5), 40-43.

European Comitee for Standardization. (2005a). Eurocode 3: Design of steel structures - Part 1-1: General rules and rules for buildings. (EN 1993-1-1:2005).

European Comitee for Standardization. (2005b). Eurocode 3: Design of steel structures - Part 1-8: Design of joints (EN 19931-8:2005).

Giżejowski, G. M., Szczerba, R., Gajewski, M. D., \& Stachura, Z. (2017). Buckling resistance assessment of steel I-section beam-columns not susceptible to LT-buckling. Archives of Civil and Mechanical Engineering, 17(2), 205-221. https://doi.org/10.1016/j.acme.2016.09.003

Yoo, C., \& Lee, S. (2011). Stability of structures (1st ed.). Butterworth-Heinemann.

Kala, Z. (2016). Global sensitivity analysis in stability problems of steel frame structures. Journal of Civil Engineering and Management, 22(3), 417-424. https://doi.org/10.3846/13923730.2015.1073618

Kim, S. E., \& Truong, V. H. (2020). Reliability evaluation of semirigid steel frames using advanced analysis. Journal of Structural Engineering, 146(5).

https://doi.org/10.1061/(ASCE)ST.1943-541X.0002616
Králik, J. (2013). Deterministic and probabilistic analysis of steel frame bracing system efficiency. Applied Mechanics and Materials, 390, 172-177.

https://doi.org/10.4028/www.scientific.net/AMM.390.172

Morkhade, S. G., \& Gupta, L. M. (2015). Analysis of steel I-beams with rectangular web openings: Experimental and finite element investigation. Engineering Structures and Technologies, $7(1), 13-23$. https://doi.org/10.3846/2029882X.2015.1085332

Park, S., \& Yeo, D. (2017). Second-order effects on wind-induced structural behavior of high-rise steel buildings. Journal of Structural Engineering, 144(2).

https://doi.org/10.1061/(ASCE)ST.1943-541X.0001943

Silva, L. S., Simões, R., \& Gervásio, H. (2013). Design of steel structures. Revised second impression. European Convention for Constructional Steelwork, Portugal.

The Steel Construction Institute. (2009). Steel Building Design: Worked examples for students. In accordance with Eurocodes and the UK National Annexes. United Kingdom.

Truong, V. H., Nguyen P. C., \& Kim, S. E. (2017). An efficient method for optimizing space steel frames with semi-rigid joints using practical advanced analysis and the micro-genetic algorithm. Journal of Constructional Steel Research, 128, 416-427. https://doi.org/10.1016/j.jcsr.2016.09.013

Turskis, Z., Urbonas, K., \& Daniūnas, A. (2019). A hybrid fuzzy group multi-criteria assessment of structural solutions of the symmetric frame alternatives. Symmetry, 11(2), 261.

https://doi.org/10.3390/sym11020261

Walport, F., Gardner, L., Real, E., Arrayago, I., \& Nethercot, D. A. (2019). Effects of material nonlinearity on the global analysis and stability of stainless steel frames. Journal of Constructional Steel Research, 152, 173-182. https://doi.org/10.1016/j.jcsr.2018.04.019

Zavadskas, E. K., Turskis, Z., Volvačiovas, R., \& Kildiene, S. (2013). Multi-criteria assessment model of technologies. Studies in Informatics and Control, 22(4), 249-258. https://doi.org/10.24846/v22i4y201301

Ziemian, R. (2010). Guide to stability design criteria for metal structures (6th ed.). John Wiley \& Sons. https://doi.org/10.1002/9780470549087 